\title{
Dehorning of cattle in the EU Member States: A quantitative survey of the current practices
}

\author{
G. Cozzi ${ }^{\mathrm{a}, *}$, F. Gottardo ${ }^{\mathrm{a}}$, M. Brscic ${ }^{\mathrm{a}}$, B. Contiero ${ }^{\mathrm{a}}, \mathrm{N}_{\text {. Irrgang }}^{\mathrm{b}}$, U. Knierim ${ }^{\mathrm{b}}$, \\ O. Pentelescu ${ }^{\text {c }}$, J.J. Windig ${ }^{\mathrm{d}}$, L. Mirabito ${ }^{\mathrm{e}}$, F. Kling Eveillard ${ }^{\mathrm{e}}$, A.C. Dockes ${ }^{\mathrm{e}}$, \\ I. Veissier ${ }^{\mathrm{f}}$, A. Velarde ${ }^{\mathrm{g}}$, C. Fuentes ${ }^{\mathrm{g}}$, A. Dalmau ${ }^{\mathrm{g}}$, C. Winckler ${ }^{\mathrm{h}}$ \\ a Department of Animal Medicine, Production and Health, University of Padova, Viale dell'Università 16, 35040 Legnaro, PD, Italy \\ ${ }^{\mathrm{b}}$ Farm Animal Behaviour and Husbandry Section, University of Kassel, Nordbahnhofstrasse 1a, 37213 Witzenhausen, Germany \\ ${ }^{\mathrm{c}}$ Department of Bovine Breeding, University of Agricultural Sciences and Veterinary Medicine, 3-5 Manastur Street, 400372 Cluj-Napoca, \\ Romania \\ ${ }^{\mathrm{d}}$ Animal Breeding and Genomics Centre, Wageningen University and Research Centre, Livestock Research, Postbus 338, 6700 AH Wa- \\ geningen, The Netherlands \\ "Institut de l'Elevage, France \\ f INRA, UMR1213 Herivores Theix, 63122 St-Genes-Champanelle, France \\ ${ }^{\mathrm{g}}$ Institut de Recerca i Tecnologia Agroalimentàries (IRTA), Animal Welfare Subprogram, Veinat de Sies s/n, 17121 Monells, Girona, Spain \\ ${ }^{\mathrm{h}}$ University of Natural Resources and Life Sciences BOKU, Division Livestock Science, A-1180 Vienna, Austria
}

\section{A R T I C L E I N F O}

\section{Keywords:}

Cattle

Dehorning

Methods

Production systems

European Union

\section{A B S T R A C T}

A survey was carried out to describe the extent and current practice of cattle disbudding/ dehorning in the EU Member States. Disbudding was defined as removal of horns in calves of up to 2 months of age, whereas dehorning was defined as removal of horns in older animals. Specific questionnaires were created regarding dairy, beef, and suckler production systems and they were submitted to local experts of each country belonging to relevant institutions like universities, national farmers' associations, cattle breeders associations, farm veterinarians and practitioners. Figures on disbudding/dehorning practices were produced for each production system for both the whole European Union and the North, Centre, East and South EU macro-regions. A total of 652 questionnaires were collected and $64 \%, 24 \%$ and $12 \%$ of them related to dairy cattle, beef cattle and suckler cows, respectively. Data from the survey showed that in Europe, $81 \%$ of the dairy, $47 \%$ of the beef and $68 \%$ of the suckler currently keep disbudded/dehorned animals, while the prevalence of polled cattle is rather low, especially in the dairy cattle sector ( $5 \%$ of all cattle farms; $<1 \%$ of dairy farms). Regardless of production system, prevalence of dehorned animals is the highest in the North macro-region. Polled cattle farms are almost exclusively located in the North where polled beef breeds are raised for fattening. Dehorning is performed primarily on loose housed cattle to reduce the risk of injuries for herdmates and the stockman. Dehorning is less frequently performed in organic farms. As method of horns removal, disbudding is generally preferred over surgical removal of the horns in older cattle. Hot-iron is the most used disbudding method especially in the North and Centre. Use of caustic paste is reported more frequently in the South and the East. In the large majority of EU farms, the stockman is the person in charge for disbudding and some kind of medication for pain relief is administered to the animals only in a small percentage of

\footnotetext{
* Corresponding author.

E-mail address: giulio.cozzi@unipd.it (G. Cozzi).
} 
farms ( $<30 \%$ ). Surgical dehorning of more aged cattle is mainly performed with the wire/ saw method. Compared to disbudding, it is more often carried out by a veterinarian and pre- and post operative medications ( $44 \%$ farms) is also more common.

(c) 2015 Elsevier B.V. All rights reserved.

\section{Introduction}

Animal welfare is becoming an important issue in the European scenario of livestock husbandry and farm practices. Together with other changes of the phenotype that have become a common practice in the modern animal husbandry (e.g. beak trimming of laying hens, castration and tail docking of piglets), the removal of the horn buds or of the horn in cattle has been under the scrutiny of public opinion. Dehorning of cattle is common practice particularly in modern dairy holdings, in order to reduce the risk for the stockpersons during routine management practices and veterinary examinations (Duffield, 2008). Horned cows can also cause injuries to herd mates during aggressive interactions and competition at the feeding gate (NFACC, 2009; AVMA, 2010).

So far, available data on dehorning practices have been gathered only from dairy farms of traditional dairy areas of North America and Europe (Fulwider et al., 2008; Gottardo et al., 2011; Hoe and Ruegg, 2006; Misch et al. 2007; Stock et al., 2013; Vasseur et al., 2010). No published information is available for beef and suckling herds.

In the European Union, the practice of dehorning is regulated by the European Council Directive 98/58/EC (1998), laying down the general minimum standards for the protection of farm animals. According to the Directive, animals should not experience unnecessary pain, suffering or injury. As all member states and the European Union are contracting parties to the European Convention for the Protection of Animals Kept for Farming Purposes, the Recommendation concerning Cattle (Council of Europe Standing Committee, 1988) applies. It lays down that except for chemical and heat cauterization in calves under four weeks of age, disbudding/dehorning shall be carried out under local anaesthesia by a veterinary surgeon or any other person qualified according to domestic legislation. However, national rules regarding disbudding/dehorning are rather inhomogeneous (Cozzi et al., 2009). Moreover, information on the actual implementation of possible legal standards and on current practices are very scarce. Therefore, in order to broaden the existing knowledge to which extent cattle are dehorned and the way the procedures are carried out, a quantitative survey was carried out in the EU Member States within the tender project Alternatives to Castrations and Dehorning (SANCO, 2009) funded by Directorate General for Health \& Consumer of the European Commission. Main tasks of the survey were to assess how many farms are dehorning their cattle, why and how the procedure is carried out. Figures on dehorning practices and on the prevalence of disbudding/dehorning were produced for the European Union as all and comparisons could be made between the 4 EU macro-regions (North, Centre, East and South) and between production systems (dairy, beef and suckler).

\section{Materials and methods}

The survey covered the whole European Union by establishing contacts in each Member State with local experts from relevant institutions like universities, national farmers' associations, cattle breeders associations, farm veterinarians and practitioners. Disbudding was defined as removal of the horn buds in calves of up to 2 months of age, whereas dehorning was defined as removal of the horns in older animals.

\subsection{Questionnaires}

Three specific questionnaires were created and submitted to local experts of dairy, beef and suckler herds husbandry in all Member States. Beef farms were classified as specialized units addressed to the fattening and finishing of young cattle for beef production. Suckler herds were productive units that maintain a breeding herd and usually sell weaned calves to beef farms. In each EU country, the questionnaires gathered information on herd management and housing systems. Specific questions were addressed towards the dehorning practices and the presence of polled cattle. Further questions were focused on the method used to disbud/dehorn, the person in charge of the procedure, the use of medications pre- or/ and post-dehorning (sedation, local anaesthesia, analgesia and their combination) and the postoperative use of a local disinfectant. A last question addressed the main reason for carrying out the practice choosing among 6 alternatives answers: 1 . to reduce the risk of injuries for the stockman; 2. to reduce the risk of injuries among herdmates; 3 . to allow an easier cattle handling; 4 . to adjust cattle to existing housing facilities (i.e. feeding rack); 5 . to reduce carcass depreciation due to skin lesions; 6 . other reasons (reported by the respondent).

\subsection{Data collection and statistical analysis}

Data were collected from January to April 2009 and processed at European level according to the production system (dairy, beef and suckler). Further data processing considered a geographical factor by allocating the EU countries in 4 macro-regions as follows: North (Denmark, Estonia, Finland, Ireland, Latvia, Lithuania, Sweden and United Kingdom); Centre (Austria, Belgium/Luxemburg, Czech Republic, France, Germany, Netherlands and Slovakia); East (Bulgaria, Hungary, Poland, Romania and Slovenia); South (Cyprus, Greece, Italy, Portugal and Spain).

Overall results for the European Union and the four macro-regions were calculated weighing data from each Member State by the number of cattle reared in the same country according to EUROSTAT 2007. Data reported for 
dairy were used to define the national dairy cattle population. Suckler cows population in the different Member states was estimated using data reported for 'non dairy cows'. Since there were no official data about the national beef cattle population, this was estimated as a half of the number of young cattle with less than two years assuming that young replacements of dairy and suckler cows (female calves and heifers) would represent $50 \%$ of the young stocks.

Statistical analyses were performed using the SAS program (SAS 9.1, SAS Institute, Inc., Cary, NC, USA). Chisquare tests with Marascuillo procedure were performed to simultaneously test the differences between all pairs of proportions of a given independent variable related to the dehorning practice with the levels of classifications factors, such as production systems and EU macro-regions. A similar approach was used for the analysis of the disbudding/dehorning method considering the person in charge (stockman, veterinarian or other) and pharmaceutical treatment (use and type of medication) as classification factors. When there was a significant difference among levels $(P<0.05)$ odd ratios $(O R)$ and 95\% confidence interval $(\mathrm{CI})$ were calculated. Simple Pearson correlation between the direct involvement of a veterinary in the dehorning procedure and the use of some medication were calculated by PROC CORR.

\section{Results}

\subsection{General information on cattle production systems from the respondents}

In total, 652 questionnaires were collected over the 4 months period (Table 1). Almost two thirds of the questionnaires reported information on dairy cattle farms while beef and suckler herds experts contributed $24 \%$ and $12 \%$ of the total number of collected questionnaires, respectively. When the geographical origin of the dataset was taken into account, $41 \%$ of the questionnaires came from countries included in the Eastern macro-region, 31\% from the Centre, $20 \%$ from the South and the remaining $7 \%$ from Northern Europe.
Regardless of production system, loose housing was by far the predominant cattle housing system that appeared in reported questionnaires (Table 1 ). Loose housing systems were more frequent in beef farms $(P<0.001)$ while tie stall farms were a more common feature of small scale dairy holdings $(P<0.001)$ mainly located in the East and Centre macro-regions. Permanent pasture grazing was reported to be a rearing system only for suckler herds and its low prevalence was equally distributed across macroregions (Table 1 ).

Conventional production schemes prevailed throughout the EU ( $97 \%$ of farms) with the highest proportions of organic farms reported for the North (6\%), and Centre (4\%) macro-regions (Table 1). However for both production schemes, no significant effect due to herd type and macroregions was reported.

\subsection{Dehorning practice and production system}

The overall prevalence of farms with dehorned cattle was about $61 \%$ (Table 2). The practice of dehorning was less frequent in beef cattle farms as compared to dairy and suckler herds $(\mathrm{OR}=0.63)$. The overall prevalence of farms with polled cattle was very low (5\%), with a - though not significantly - lower proportion of dairy farms $(<1 \%)$.

Farms with loose housing system had a higher prevalence of dehorning than tie-stall farms (67.0 vs $17.1 \%$; $P<0.001$ ) and the calculated likelihood to be dehorned for loose housed animals was almost four times greater than that of tethered ones ( $\mathrm{OR}=3.94$ and 95\% C.I. 2.50-6.21). However, for both housing systems, dehorning was less frequent for beef as compared to dairy and suckler herds (loose housing: beef vs dairy + suckler OR $=0.63$ and $95 \% \mathrm{C}$. I. 0.56-0.77; tie-stalls: beef vs dairy + suckler $\mathrm{OR}=0.19$ and 95\% C.I. $0.10-0.37 ; P<0.001)$. Dehorning was reported to be more frequent in conventional than in organic farms (62.6 vs $22.1 \% ; P<0.001$ ) The difference between these two production schemes was more pronounced in beef cattle farms than in dairy and suckler (conventional scheme: beef vs dairy+suckler $\mathrm{OR}=0.71$ and 95\% C.I. 0.57-0.88; organic scheme: beef vs dairy+suckler $\mathrm{OR}=0.10$ and $95 \%$ C.I. $0.04-0.26 ; P<0.001$ ).

Seventy-five percent of the farms who dehorn their

Table 1

Number of questionnaires (expert responses) and reported information about prevalence of cattle housing systems and production schemes relating to production system and European Union macro-regions.

\begin{tabular}{|c|c|c|c|c|c|c|c|c|c|c|}
\hline \multirow[t]{2}{*}{ Item } & \multirow[t]{2}{*}{ Overall } & \multicolumn{3}{|c|}{ Production system } & \multirow[t]{2}{*}{$P$} & \multicolumn{4}{|c|}{ EU macro-region } & \multirow[t]{2}{*}{$P$} \\
\hline & & Beef & Dairy & Suckler & & North & Centre & East & South & \\
\hline Questionnaires, $n$ & 652 & 157 & 419 & 76 & & 47 & 205 & 269 & 131 & \\
\hline \multicolumn{11}{|l|}{ Housing system: } \\
\hline Loose housing, \% of farms & $80.7^{\alpha}$ & $91.0^{\mathrm{a}}$ & $66.8^{\mathrm{b}}$ & $72.8^{\mathrm{b}}$ & $<0.001$ & $90.5^{\mathrm{a}}$ & $78.2^{\mathrm{ab}}$ & $64.1^{\mathrm{b}}$ & $85.5^{\mathrm{a}}$ & $<0.001$ \\
\hline Tie stall, \% of farms & $17.1^{\beta}$ & $9.0^{\mathrm{b}}$ & $33.1^{\mathrm{a}}$ & $12.7^{\mathrm{b}}$ & $<0.001$ & $5.9^{\mathrm{b}}$ & $20.1^{\mathrm{ab}}$ & $35.2^{\mathrm{a}}$ & $11.3^{\mathrm{b}}$ & $<0.001$ \\
\hline Permanent grazing, \% of farms & $2.2^{\gamma}$ & 0 & 0 & 14.5 & & 3.6 & 1.6 & 0.7 & 3.1 & 0.709 \\
\hline \multicolumn{11}{|l|}{ Production scheme: } \\
\hline Conventional, $\%$ of farms & $96.6^{\alpha}$ & 97.5 & 96.4 & 94.0 & 0.254 & 94.2 & 98.5 & 99.5 & 98.1 & 0.100 \\
\hline Organic, \% of farms & $3.4^{\beta}$ & 2.5 & 3.5 & 6.0 & 0.450 & 5.8 & 3.5 & 0.3 & 1.9 & 0.151 \\
\hline
\end{tabular}

a,b,c: values within a row with different superscripts for a given classification factor differ at the reported $P$ value. $\alpha, \beta, \gamma$ : values within a column with different superscripts for a given variable differ at $P<0.001$. 
Table 2

Effect of production system on the prevalence of disbudding/dehorning and methods used in the European Union.

\begin{tabular}{|c|c|c|c|c|c|c|c|c|}
\hline & \multirow[t]{2}{*}{ Overall } & \multicolumn{3}{|c|}{ Production system } & \multirow[t]{2}{*}{$P$} & \multirow[t]{2}{*}{ Contrasts } & \multirow[t]{2}{*}{ Odds ratio } & \multirow[t]{2}{*}{ 95\% C.I. } \\
\hline & & Beef (B) & Dairy (D) & Suckler (S) & & & & \\
\hline Farms with dehorned cattle, $\%$ & 60.6 & $46.8^{\mathrm{b}}$ & $80.7^{\mathrm{a}}$ & $67.6^{\mathrm{a}}$ & $<0.001$ & B vs $(D+S)$ & 0.63 & $0.51-0.79$ \\
\hline Farms with polled cattle, \% & 4.9 & 7.3 & 0.9 & 4.7 & 0.135 & - & - & - \\
\hline \multicolumn{9}{|l|}{ Disbudding: } \\
\hline $\begin{array}{l}\% \text { of farms with dehorned cattle } \\
\text { Method of disbudding: }\end{array}$ & 74.7 & $71.3^{b}$ & $88.8^{\mathrm{a}}$ & $57.8^{b}$ & $<0.001$ & $\mathrm{D}$ vs $(\mathrm{B}+\mathrm{S})$ & 1.38 & $1.22-1.56$ \\
\hline Hot-iron, \% of farms & $71.0^{\alpha}$ & $68.4^{\mathrm{ab}}$ & $80.4^{\mathrm{a}}$ & $60.8^{\mathrm{b}}$ & 0.011 & D vs $S$ & 1.31 & $1.09-1.58$ \\
\hline Caustic paste, $\%$ of farms & $25.7^{\beta}$ & $28.2^{\mathrm{ab}}$ & $16.0^{\mathrm{b}}$ & $36.2^{\mathrm{a}}$ & 0.006 & D vs S & 0.44 & $0.26-0.75$ \\
\hline Scoop/tube, \% of farms & $2.7^{\gamma}$ & 2.6 & 3.5 & 1.7 & 0.879 & - & - & - \\
\hline Use of medications ${ }^{1}, \%$ of farms & 27.6 & $26.2^{\mathrm{ab}}$ & $35.5^{\mathrm{a}}$ & $16.3^{\mathrm{b}}$ & 0.008 & D vs S & 2.25 & $1.34-3.78$ \\
\hline \multicolumn{9}{|l|}{ Dehorning } \\
\hline $\begin{array}{l}\% \text { of farms with dehorned cattle } \\
\text { Method of dehorning: }\end{array}$ & 24.7 & $27.9^{\mathrm{a}}$ & $11.1^{\mathrm{b}}$ & $41.0^{\mathrm{a}}$ & $<0.001$ & $\mathrm{D}$ vs $(\mathrm{B}+\mathrm{S})$ & 0.32 & $0.18-0.57$ \\
\hline Wire/saw, \% of farms & $72.5^{\alpha}$ & $68.8^{\mathrm{b}}$ & $83.8^{\mathrm{a}}$ & $62.7^{b}$ & 0.004 & $\mathrm{D}$ vs $(\mathrm{B}+\mathrm{S})$ & 1.27 & $1.12-1.45$ \\
\hline Others $^{2}, \%$ of farms & $26.7^{\beta}$ & $30.4^{\mathrm{ab}}$ & $15.7^{\mathrm{b}}$ & $36.0^{\mathrm{a}}$ & 0.004 & D vs $S$ & 0.44 & $0.26-0.75$ \\
\hline Use of medications ${ }^{1}, \%$ of farms & 43.4 & $37.9^{\mathrm{b}}$ & $57.2^{\mathrm{a}}$ & $35.3^{b}$ & $<0.001$ & $\mathrm{D}$ vs $(\mathrm{B}+\mathrm{S})$ & 1.56 & $1.22-2.00$ \\
\hline
\end{tabular}

a,b,c: values within a row with different superscripts for a given classification factor differ at the reported $P$ value.

$\alpha, \beta, \gamma$ : values within a column with different superscripts for a given variable differ at $P<0.001$.

1: sedation, local anaesthesia, analgesia or a combination among these main treatments.

2: dehorning shears, choppers, grinders and guillotines.

cattle reported disbudding as the method for horn removal (Table 2). The use of disbudding showed the highest prevalence in dairy herds $(P<0.001)$. Hot-iron cauterization was the main disbudding method followed by caustic paste and scoop/tube in descending order $(P<0.001)$. The use of hot iron disbudding was more likely in dairy than in suckler herd farms $(\mathrm{OR}=1.31 ; P=0.011)$ whereas caustic paste showed an opposite trend $(\mathrm{OR}=0.44 ; P<0.01)$ with beef cattle farms always intermediate (Table 2). Less than $30 \%$ of farms performing disbudding used some medications before and/or after the procedure and the likelihood of a drug treatment was more than double in dairy than suckler herds $(\mathrm{OR}=2.25 ; P<0.009)$.

Dehorning of cattle (older than 2 months) had an overall prevalence of $24.7 \%$ and it was mostly performed in suckler and beef cattle farms $(P<0.001)$ (Table 2$)$. Wire/ saw was the main method of dehorning and its use was more frequent in dairy than in suckler and beef cattle farms $(P<0.005)$. The use of some medication before and/ or after the procedure was reported by more than $40 \%$ of farms performing the dehorning and the likelihood of a drug treatment was higher in dairy than in beef and suckler farms $(\mathrm{OR}=1.56 ; P<0.001)$.

\subsection{Dehorning practice and EU geographic areas}

There was a significant effect of the geographic area $(P<0.001)$ on the prevalence of cattle dehorning within EU (Table 3). The highest prevalence was reported for the North macro-region (85.6\% of the farms), followed by the Centre (61.2\%) and by East and South in descending order (46.4 and $36.6 \%$, respectively). In the North macro-region, there was also the highest percentage of farms rearing polled cattle, whereas these farms were rarely reported in the other regions $(P<0.001)$. At this regard, it must be noticed that the same farm might host dehorn and polled cattle and therefore it could have been counted in both categories.
Moving from North to South, there was a decreasing trend for the percentage of farms performing disbudding, according to a significant macro-region effect $(P<0.001)$. Hot-iron cauterization was reported as the main disbudding method used in the North and in the Centre, while caustic paste was prevailing in the East and the South (Table 3). There was no difference across EU macro-regions on the use of some medications around disbudding.

A higher prevalence of farms dehorning cattle older than 2 months was reported in the South and in the East macro-regions $(P<0.001)$, where the procedure was mostly performed using the wire/saw method. This method was also common in the Centre and the North but in both macro-regions there was a greater use of alternative tools like dehorning shears, choppers, grinders and guillotines. The use of some medications before and/or after the procedure showed a significant effect of the geographical region $(P<0.001)$, being higher in the North and East than in the South area (Table 3).

\subsection{Person in charge of the procedure and use of medication}

Regardless of the method used to disbud the young calves, the stockman was reported as the person most frequently performing the procedure (Table 4). Numerically, caustic paste was reported to be almost exclusively applied by farm personnel, while as compared to this method, hot-iron and scoop/tube disbudding were more frequently carried out by the farm veterinarian. The involvement of an external technical assistants (included in the category 'other') was of only minor importance. The use of medication was significantly dependent on the method used for calf disbudding $(P<0.001)$. Prevalence of the use of drugs was reported to be the highest with hotiron cauterization (51\%), it was halved in farms using scoop/tube (26\%) and the lowest in the case of the use of caustic paste (6\%). A combination of sedation and local 
Table 3

Effect of geographic area on the prevalence of disbudding/dehorning and methods used in the European Union.

\begin{tabular}{|c|c|c|c|c|c|}
\hline & \multicolumn{4}{|c|}{ EU macro-regions } & \multirow[t]{2}{*}{$P$} \\
\hline & North & Centre & East & South & \\
\hline Farms with dehorned cattle, \% & $85.6^{\mathrm{a}}$ & $61.2^{\mathrm{b}}$ & $46.4^{\mathrm{bc}}$ & $36.6^{\mathrm{c}}$ & $<0.001$ \\
\hline Farms with polled cattle, $\%$ & $16.9^{\mathrm{a}}$ & $1.4^{\mathrm{b}}$ & $1.9^{\mathrm{b}}$ & $0.8^{\mathrm{b}}$ & $<0.001$ \\
\hline \multicolumn{6}{|l|}{ Disbudding: } \\
\hline$\%$ of farms with dehorned cattle & $87.7^{\mathrm{a}}$ & $79.2^{\mathrm{ab}}$ & $64.0^{\mathrm{bc}}$ & $53.7^{\mathrm{c}}$ & $<0.001$ \\
\hline \multicolumn{6}{|l|}{ Method of disbudding: } \\
\hline Hot-iron, \% of farms & $91.1^{\mathrm{a}}$ & $83.7^{\mathrm{a}}$ & $40.0^{\mathrm{b}}$ & $35.1^{\mathrm{b}}$ & $<0.001$ \\
\hline Caustic paste, $\%$ of farms & $6.7^{\mathrm{b}}$ & $16.2^{\mathrm{b}}$ & $52.3^{\mathrm{a}}$ & $57.2^{\mathrm{a}}$ & $<0.001$ \\
\hline Scoop/tube, \% of farms & 2.2 & 0.1 & 7.7 & 7.7 & 0.060 \\
\hline Use of medications ${ }^{1}, \%$ of farms & 25.4 & 32.2 & 21.5 & 22.8 & 0.310 \\
\hline \multicolumn{6}{|l|}{ Dehorning } \\
\hline$\%$ of farms with dehorned cattle & $12.3^{\mathrm{c}}$ & $20.8^{\mathrm{bc}}$ & $36.0^{\mathrm{ab}}$ & $42.9^{\mathrm{a}}$ & $<0.001$ \\
\hline \multicolumn{6}{|l|}{ Method of dehorning: } \\
\hline Wire/saw, \% of farms & $54.1^{\mathrm{b}}$ & $70.9^{\mathrm{b}}$ & $93.8^{\mathrm{a}}$ & $87.3^{\mathrm{a}}$ & $<0.001$ \\
\hline Others $^{2}, \%$ of farms & $42.2^{\mathrm{a}}$ & $29.1^{\mathrm{a}}$ & $6.2^{\mathrm{b}}$ & $12.7^{\mathrm{b}}$ & $<0.001$ \\
\hline Use of medications ${ }^{1}, \%$ of farms & $52.5^{\mathrm{a}}$ & $41.4^{\mathrm{ab}}$ & $56.8^{\mathrm{a}}$ & $28.1^{\mathrm{b}}$ & $<0.001$ \\
\hline
\end{tabular}

a,b,c: values within a row with different superscripts for a given classification factor differ at the reported $P$ value.

1: sedation, local anaesthesia, analgesia or a combination among these main treatments.

2: dehorning shears, choppers, grinders and guillotines.

Table 4

Person in charge of disbudding/dehorning and use of medications and postoperative disinfection.

\begin{tabular}{|c|c|c|c|c|c|c|c|c|c|}
\hline \multirow[t]{3}{*}{ Method of dehorning } & \multicolumn{3}{|c|}{ Person in charge } & \multicolumn{5}{|c|}{ Use of medications } & \multirow{3}{*}{$\begin{array}{l}\text { Postoperative } \\
\text { disinfection }\end{array}$} \\
\hline & \multirow[b]{2}{*}{ Stockman } & \multirow[b]{2}{*}{ Veterinarian } & \multirow[b]{2}{*}{$\begin{array}{l}\text { Technical } \\
\text { assistant }\end{array}$} & \multirow[b]{2}{*}{$\begin{array}{l}\text { (\% of } \\
\text { farm) }\end{array}$} & \multicolumn{4}{|c|}{ Type of medication (\% of total medications) } & \\
\hline & & & & & $\mathrm{SED}^{1}$ & LA & AG & COMB & \\
\hline \multicolumn{10}{|l|}{ Disbudding: } \\
\hline Hot-iron, \% of farms & $71.7^{\mathrm{a}}$ & $24.7^{\mathrm{b}}$ & $3.6^{\mathrm{c}}$ & $50.7^{\alpha}$ & $24.8^{\mathrm{b}}$ & $26.6^{\mathrm{b}}$ & $2.4^{\mathrm{c}}$ & $46.2^{\mathrm{a}}$ & $59.9^{\alpha}$ \\
\hline $\begin{array}{l}\text { Caustic paste, \% of } \\
\text { farms }\end{array}$ & $92.3^{\mathrm{a}}$ & $2.6^{\mathrm{b}}$ & $5.1^{\mathrm{b}}$ & $5.6^{\gamma}$ & $21.2^{\mathrm{ab}}$ & $28.8^{\mathrm{a}}$ & $12.5^{\mathrm{b}}$ & $37.5^{\mathrm{a}}$ & $21.8^{\beta}$ \\
\hline $\begin{array}{l}\text { Scoop/tube, \% of } \\
\text { farms }\end{array}$ & $59.9^{\mathrm{a}}$ & $39.6^{\mathrm{b}}$ & $0.5^{\mathrm{c}}$ & $25.9^{\beta}$ & $22.6^{\mathrm{b}}$ & $49.9^{\mathrm{a}}$ & $20.0^{\mathrm{bc}}$ & $7.5^{\mathrm{c}}$ & $66.6^{\alpha}$ \\
\hline \multicolumn{10}{|l|}{ Dehorning: } \\
\hline $\begin{array}{l}\text { Wire/saw, \% of } \\
\text { farms }\end{array}$ & $48.6^{\mathrm{a}}$ & $47.3^{\mathrm{a}}$ & $4.1^{b}$ & 55.8 & $22.3^{\mathrm{b}}$ & $32.0^{\mathrm{ab}}$ & $3.6^{c}$ & $42.1^{\mathrm{a}}$ & 72.4 \\
\hline Other $^{2}, \%$ of farms & $32.7^{\mathrm{b}}$ & $61.4^{\mathrm{a}}$ & $5.9^{\mathrm{c}}$ & 52.5 & $13.6^{\mathrm{b}}$ & $34.3^{\mathrm{a}}$ & $12.7^{\mathrm{b}}$ & $39.5^{\mathrm{a}}$ & 71.8 \\
\hline
\end{tabular}

1: $\mathrm{SED}=$ sedation; $\mathrm{LA}=$ local anaesthesia; $\mathrm{AG}=$ analgesia; $\mathrm{COMB}=$ combination among SED and/or LA and/or AG.

a,b,c: values within a row with different superscripts for a given classification factor differ at $P<0.001$.

$\alpha, \gamma, \beta$ : values within a column with different superscripts for a given variable differ at $P<0.001$.

2: dehorning shears, choppers, grinders and guillotines.

Table 5

Main reasons for cattle dehorning according to production system and EU macro-region (\% of total responses).

\begin{tabular}{|c|c|c|c|c|c|c|c|c|c|c|}
\hline & \multirow[t]{2}{*}{ Overall } & \multicolumn{3}{|c|}{ Production system } & \multirow[t]{2}{*}{$P$} & \multicolumn{4}{|c|}{ EU macro-regions } & \multirow[t]{2}{*}{$\mathrm{P}$} \\
\hline & & Beef & Dairy & Suckler & & North & Centre & East & South & \\
\hline To reduce the risk of injures among herdmates & $53.6^{\alpha}$ & $48.6^{\mathrm{b}}$ & $65.7^{\mathrm{a}}$ & $46.8^{\mathrm{b}}$ & 0.016 & $1.1^{\mathrm{b}}$ & $70.4^{\mathrm{a}}$ & $64.7^{\mathrm{a}}$ & $70.0^{\mathrm{a}}$ & $<0.001$ \\
\hline To reduce the risk of injures for the stockman & $23.6^{\beta}$ & $27.1^{\mathrm{b}}$ & $6.5^{\mathrm{c}}$ & $45.4^{\mathrm{a}}$ & $<0.001$ & $54.1^{\mathrm{a}}$ & $4.4^{\mathrm{c}}$ & $12.8^{\mathrm{c}}$ & $40.7^{\mathrm{b}}$ & $<0.001$ \\
\hline To allow easier handling & $13.4^{\beta \gamma}$ & 10.0 & 15.5 & 21.1 & 0.122 & $23.3^{\mathrm{b}}$ & $2.1^{\mathrm{c}}$ & $6.6^{\mathrm{c}}$ & $34.3^{\mathrm{a}}$ & $<0.001$ \\
\hline To adjust cattle to existing housing facilities & $6.8^{\gamma}$ & 7.4 & 7.5 & 3.6 & 0.580 & $17.1^{\mathrm{a}}$ & $*$ & $17.2^{\mathrm{a}}$ & $4.2^{\mathrm{b}}$ & 0.007 \\
\hline To reduce carcass depreciation due to skin lesions & $5.1^{\gamma}$ & 8.4 & $*$ & 3.6 & 0.232 & $*$ & $*$ & * & 27.7 & \\
\hline Other ${ }^{1}$ & $12.4^{\beta \gamma}$ & $8.4^{\mathrm{b}}$ & $13.3^{\mathrm{ab}}$ & $24.1^{\mathrm{a}}$ & 0.005 & 34.0 & $*$ & $*$ & 24.7 & 0.118 \\
\hline
\end{tabular}

$\alpha, \beta, \gamma$ : values within a column with different superscripts for a given variable differ at $P<0.001$

a,b,c: values within a row with different superscripts for a given classification factor differ at the reported $P$ value.

*Never reported as main reason.

1: Welfare purpose, obligations from cattle markets, slaughterhouses and insurances. 
anaesthesia was the protocol most frequently applied before the procedure by farms using hot-iron cauterization (Table 4). Local anaesthesia prevailed when using scoop/ tube. As regards disbudding methods, postoperative use of a topic disinfectant was more frequent than preoperative use of some medication. Prevalence of local disinfection was higher when using hot cauterization or scoop/tube (Table 4).

Dehorning of cattle older than two months was reported to be carried out with a greater direct intervention by veterinary practitioners, often with the assistance of the farm personnel (Table 4). The veterinarian is mostly in charge of horn removal when using alternative tools like dehorning shears, choppers and guillotines. Regardless of the method, the prevalence of farms using some medication and postoperative local disinfection are above 55\% and $70 \%$, respectively. Regarding preoperative medications local anaesthesia alone or combined with a sedation were reported as the most frequent protocols (Table 4).

\subsection{Main reasons for dehorning}

Disbudding/dehorning was primarily considered an effective solution to reduce the risk of injuries among loose housed cattle (Table 5). This motivation was more frequently mentioned with regard to dairy farming as compared to other production systems $(P<0.02)$. Lowering the risk of injuries for the stockman was reported as main reason to perform dehorning by $24 \%$ of the respondents and this motivation was particularly relevant for suckler herds $(P<0.001)$.

To allow an easier handling of cattle (13\%) and other reasons, such as welfare considerations and obligations from cattle markets, slaughterhouses or insurances (12\%), were numerically but not significantly less important than stockman's safety. When the EU-macro-region was considered as classification factor, the reduced risk of injuries among herdmates was mostly reported as the main reason for all regions except for the North $(P<0.001)$ where reducing the risk of injuries for the stockman was prevailing $(P<0.001)$. Multiple answers to this question were most common in the South than in the other macro-regions.

\section{Discussion}

The different number of questionnaires collected according to the production system seems to reflect the interest for dehorning practice among dairy, beef and suckler farms with a clear prevalence of the dairy sector.

Data from the survey show that the practice of dehorning is quite common in Europe and it is more frequently performed in dairy and suckler herds reared in the North macro-region. The high prevalence of dehorning recorded for the dairy farms is consistent with the results of recent surveys carried out in US, Italy and Canada (Fulwider et al., 2008; Gottardo et al., 2011; Misch et al., 2007). The practice of dehorning is instead less frequent in beef farms and this low prevalence mainly arises from the South and East macro-regions. Even though some caution must be applied in interpreting data from the beef and suckler survey due to the fewer questionnaires gathered, these results appear plausible. Mediterranean countries do not dehorn domestic cattle raised for beef production (Cozzi et al., 2009) and countries like Italy and Spain cover their national deficit of red meat by fattening young male stocks mainly imported from France and Eastern European countries (Cozzi, 2007). France has a little tradition in the practice of beef cattle dehorning, whereas in the East macro-region beef cattle is still often kept horned in small scale tie stall farms.

Rearing polled cattle genotypes as an alternative to cattle dehorning has been reported with a low prevalence exclusively in the North macro-region where polled beef cattle breeds such as Aberdeen Angus, Hereford, Galloway are kept for calves production. The introduction of the polled gene has so far been of lower importance for dairy cattle, but may be reinforced in future (Götz et al., 2015; Windig et al., 2015).

According to European Commission Directorate-General for Agriculture and Rural Development (DG-AGRI, 2010), in 2007 there were 2.4 million heads of organic certified cattle in the EU-27, representing $2.7 \%$ of the total cattle population. This value is quite close to that calculated from our dataset (3.4\%). As regards cattle dehorning, the EU regulation EC No. 889/2008 on organic farming sets that this practice, along with other mutilations (i.e. taildocking), shall not be carried out routinely. The disbudding/dehorning practice and the presence of hornless dairy cattle are banned by Demeter International Production Standards (2009). In line with these principles, the outcomes of this survey showed that cattle raised in organic farms have a lower likelihood of being dehorned when compared to conventional farms ( $\mathrm{OR}=0.35$ and $95 \%$ C.I. $0.24-0.53$ ) and the practice is rarely used by beef farmers.

Disbudding is mainly performed by farm personnel and the use of pre- and post-operative medications is limited. Likely veterinarians are mostly not involved for economical reasons and because it is mostly not legally required (Cozzi et al., 2009). Moreover, veterinary skill is not perceived necessary, as for instance, for thermal cauterization it is reported that it does not require haemostasis and has minimal post-operative complications (Rebhun, 1995). The low use of local anaesthesia and sedation is partly associated with the operator, because in some countries use of anaesthetics or sedatives is legally restricted to veterinarians. Moreover, many farmers do not regard the procedure to be significantly painful for the animals (Kling-Eveillard et al., 2015). The even lower use of any analgesics presumably is linked to a generally low state of knowledge, even among veterinarians (Meintjes, 2012).

Some cattlemen consider caustic paste less hazardous than hot-iron, although its incorrect application may cause serious tissue damage to the calf (Stafford and Mellor, 2005) as well as to operators. Caustic substances have shown to be almost exclusively applied by the stockman and the lack of an immediate defence reaction by the calf could partially explain their rare combination with preoperative medications. In contrast, the marked calf reaction during hot iron disbudding makes the disbudding of sedated or anesthetized calves easier for the operator 
(Caray et al., 2015; Stilwell et al., 2010). The highest prevalence of chemical cauterization observed in the East and South macro-regions could have several explanations: on the one hand this method is not allowed or not recommended in several countries of North and Centre, on the other hand its frequency tends to increase in countries where farmers are not legally allowed to detain and directly administer drugs used for pain relief. Moreover, the risk of unwanted tissue damage due to caustic paste is reduced in regions with dry climate. Additionally, in larger herds often hot iron disbudding is preferred as the less time-consuming method that, furthermore, can be applied effectively over a longer age period of the calves, so that there might be some relationship between herd size and disbudding method.

Although disbudding by thermal or chemical cauterization is currently considered the less invasive method for dehorning cattle, the procedure has been shown to be painful for the calf, and the use of anaesthesia and analgesia is recommended (Caray et al., 2015; Stafford and Mellor, 2011; Stilwell et al., 2010). At least the use of anaesthesia is also recommended by several veterinary guidelines (AVA, 2009; AVMA, 2010), by the Canadian code of practice for the care of dairy cattle (NFACC, 2009) as well by legal standards of single EU Member States, sometimes in association with certain age limits (Cozzi et al., 2009).

In the present survey, only $20 \%, 35 \%$ and $29 \%$ of the dairy, beef and suckler farms reported the use some kind of medication prior to disbudding, but treatment protocols have shown to be inconsistent within and between EU Member States. However, the reliability of the response received need to be treated with some caution because in some cases the distinction between sedation, anaesthesia and analgesia might not have been sufficiently clear.

Horn surgical removal is often carried out on adult animals and is a more invasive procedure than disbudding. Due to type and size of the inflicted wounds it causes more pain (Irrgang et al., 2015; Stafford and Mellor, 2005) and additionally it requires a higher level of restraint. A number of countries require the application of anaesthesia for this procedure in adult cattle and sometimes also the involvement of a veterinarian (Cozzi et al., 2009). This is also true for the Recommendation Concerning Cattle adopted by the Council of Europe Standing Committee (1988). The survey confirmed that a higher percentage of farms used some kind of medication prior and after the procedure and postoperative disinfection to reduce pain and the risk of complications, although reported protocols were inconsistent across the EU. Moreover, the highest direct intervention of a veterinary surgeon was found and it was positively correlated with the use of some medication $(r=0.60 ; P<0.001)$.

Surgical horns removal is less frequent than disbudding and it is mainly performed on bought in cattle to adapt them to existing housing facilities or for safety reasons when there is a change in the farm housing system (from tie to free stall). Dehorning is also performed as therapeutic procedure on horn-injured cattle. All these reported motivations are useful to explain the geographic difference recorded in the present survey. The practice is more frequent in Mediterranean countries where import of cattle (mainly young stocks of beef breeds) is more relevant as well as in Eastern countries where many cattle farms are facing the transition from traditional tie stall to the loose housing system.

Horns removal was reported as an effective solution to reduce the risk of injuries for both cattle and stockman as well as to allow an easier handling of cattle. However the reasons for disbudding or dehorning animals were more closely investigated through focus groups (Kling-Eveillard et al., 2015). Nevertheless, cattle disbudding or dehorning can be avoided, but this requires special attention (Knierim et al., 2009; Waiblinger and Menke, 2009) or rearing polled animals (Götz et al., 2015).

\section{Conclusions}

Data from the survey showed that in EU Member States, $81 \%$ of dairy, $47 \%$ of beef and $68 \%$ of suckler herds are currently dehorned and, regardless of production systems, prevalence of dehorned animals is the highest in the North macro-region. Dehorning is performed primarily in farms with loose housing system to reduce the risk of injuries among herdmates and for stockman safety reasons. As a method of horns removal, disbudding of young calves is generally preferred over surgical dehorning of more aged cattle. The stockman is the main person in charge of calves disbudding. Surgical horns removal is performed with a more frequent use of medications and therefore it is more frequently carried out by a direct intervention of veterinary practitioners. The introduction of transnational legal standards concerning disbudding and dehorning should help to a harmonization of the current inconsistent drug protocols observed within and between countries.

\section{Conflict of interest}

Authors declare that there are no conflicts of interest related to the issue of this article.

\section{Acknowledgments}

Research supported by SANCO within the call for tender No. SANCO/2008/D5/018.

\section{References}

AVA, 2009. Policy Compendium on Cattle Health and Welfare. American Veterinary Association. http://www.ava.com.au/about-us/policy-andpositions-1 (accessed 19.03.15.).

AVMA, 2010. Welfare implications of dehorning and disbudding of cattle. American Veterinary Medical Association. http://www.avma.org/re ference/backgrounders/dehorning_cattle_bgnd.asp (accessed 19.03.15.)

Caray, D., de Boyer, des, Roches, A., Frouja, S., Andanson, S., Veissier, I., 2015. Hot-iron disbudding: stress responses and behaviour of 1- and 4-week-old calves receiving anti-inflammatory analgesia without or with sedation using xylazine. Livest. Sci. 179, 22-28. 
Cozzi, G., 2007. Present situation and future challenges of beef cattle production in Italy and the role of the research. Ital. J. Anim. Sci. 6, 389-396.

Cozzi, G., Prevedello, P., Boukha, A., Winckler, C., Knierim, U, Pentelescu, O., Windig, J., Mirabito, L., Kling-Eveillard, F., Dockes, A.C., Veissier, I., Velarde, A., Fuentes, C., Dalmau, A., 2009. D.2.1.1. Report on dehorning practices across EU member states. Alternatives to castration and dehorning (ALCASDE; SANCO/2008/D5/018). URL: 〈http://ec.europa. eu/food/animal/welfare/farm/docs/calves_alcasde_D-2-1-1.pdf) (accessed 19.03.15.).

Council of Europe Standing Committee, 1988. Recommendation concerning cattle adopted by the Standing Committee on 21 October 1988. 〈http://www.coe.int/t/e/legal_affairs/legal_co-operation/biologi cal_safety_and_use_of_animals/farming/Rec\%20cattle\%20E.asp\#To pOfPage $>$ (accessed 19.03.15.).

Demeter International Production Standards, 2009. Demeter-Biodynamic-Production-Standards. http://it.scribd.com/doc/35261033 (accessed 19.03.15.).

DG-AGRI, 2010. An analysis of the EU organic sector. http://ec.europa.eu/ agriculture/analysis/markets/organic_2010_en.pdf (accessed 19.03.15.).

Directive 98/58/EC, 1998. Council Directive 98/58/EC of 20 July 1998 concerning the protection of animals kept for farming purposes. OJ L 221, 8.8.1998, p 23.

Duffield, T., 2008. Current data on dehorning calves. In: Proceedings of the 41st Annual Conference of the American Association of Bovine Practitioners, Auburn, AL, Charlotte, NC, pp. 25-28.

Fulwider, W.K., Grandin, T., Rollin, B.E., Engle, T.E., Dalsted, N.L., Lamm, W. D., 2008. Survey of dairy management practices on one hundred thirteen North Central and Northeastern United States dairies. J. Dairy Sci. 91, 1686-1692.

Gottardo, F., Nalon, E., Contiero, B., Normando, S., Dalvit, P., Cozzi, G., 2011. The dehorning of dairy calves: practices and opinions of six hundred and thirty-nine farmers. J. Dairy Sci. 94, 5724-5734.

Götz, K.-U., Luntz, B., Robeis, J., Edel, C., Emmerling, R., Buitkamp, J., Anzenberger, H., Duda, J., 2015. Polled Fleckvieh (Simmental) cattle current state of the breeding program. Livest. Sci. 179, 80-85.

Hoe, F.G.H., Ruegg, P.L., 2006. Opinions and practices of Winsconsin dairy producers about biosecurity and animal well-being. J. Dairy Sci. 89, 2297-2308.

Irrgang, N., Zipp, K.A., Brandt, S., Knierim, U., 2015. Effects of space allowance in the waiting area on agonistic interactions and the heart rate of high ranking and low ranking horned dairy cows. Livest. Sci. 179, 47-53.

Kling-Eveillard, F., Knierim, U., Irrgang, N., Gottardo, F., Ricci, R., Dockès, A.-C., 2015. Attitudes of farmers towards dehorning. Livest. Sci. 179,
$12-21$.

Knierim, U., Irrgang, N., Roth, B.A., Gorniak, T., 2009. D2.2.1. Report on the assessment of dehorning and the keeping of horned dairy and beef cattle. Alternatives to castration and dehorning (ALCASDE; SANCO/ 2008/D5/018). URL: 〈http://ec.europa.eu/food/animal/welfare/farm/ docs/calves_alcasde_D-2-2-1.pdf (accessed 19.03.15.).

Meintjes, R.A., 2012. An overview of the physiology of pain for the veterinarian. Vet. J. 193, 344-348.

Misch, L.J., Duffield, T.F., Millman, S.T., Lissemore, K.D., 2007. An investigation into the practices of dairy producers and veterinarians in dehorning dairy calves in Ontario. Can. Vet. J. 48, 1249-1254.

NFACC, 2009. Code of practice for the care and handling of dairy cattle. National Farm Animal Care Council. http://nfacc.ca/ (accessed 19.03.15.).

Rebhun, W.C., 1995. Diseases of Dairy Cattle. Williams \& Wilkins, Media, PA, USA.

SANCO, 2009. ALCASDE Final report. Study on the improved methods for animal-friendly production, in particular on alternatives to the castration of pigs and on alternatives to the dehorning of cattle. Directorate General of Health and Consumers, Animal Health and Welfare Directorate 2009. SANCO/2008/D5/018.

Stafford, K.J., Mellor, D.J., 2005. Dehorning and disbudding distress and its alleviation in calves. Vet. J. 169, 337-349.

Stafford, K.J., Mellor, D.J., 2011. Addressing the pain associated with disbudding and dehorning in cattle. Appl. Anim. Behav. Sci. 135, 226-231.

Stilwell, G., Carvalho, R.C., Carolino, N., Lima, M.S., Broom, D.M., 2010. Effect of hot-iron disbudding on behaviour and plasma cortisol of calves sedated with xylazine. Res. Vet. Sci. 88, 188-193.

Stock, M.L., Baldridge, S.L., Griffin, D., Coetzee, J.F., 2013. Bovine dehorning: assessing pain and providing analgesic management. Vet. Clin. N. Am.: Food Anim. Pract. 29, 103-133.

Vasseur, E., Borderas, F., Cue, R.I., Lefebvre, D., Pellerin, D., Rushen, J., Wade, K.M., de Passillé, A.M., 2010. A survey of dairy calf management practices in Canada that affect animal welfare. J. Dairy Sci. 93, 1307-1315.

Waiblinger, S., Menke, C., 2009. D.2.3.1. Report on practical recommendations at farm level for keeping horned cattle and on the use of genetic solutions. Alternatives to castration and dehorning (ALCASDE; SANCO/2008/D5/018). URL: 〈http://ec.europa.eu/food/ani $\mathrm{mal} /$ welfare/farm/docs/calves_alcasde_D-2-3-1.pdf $\rangle$.

Windig, J.J., Hoving-Bolink, R.A., Veerkamp, R.F., 2015. Breeding for polledness in Holstein. Livest. Sci. 179, 96-101. 